\title{
José María López Piñero y la conservación y difusión del patrimonio histórico-médico
}

\section{María José Báguena Cervellera (*)}

(*) Instituto de Historia de la Medicina y de la Ciencia López Piñero. Universitat de València-CSIC

Dynamis

[0211-9536] 2011; 31 (1): 233-236

Si en algo coincidimos todos quienes conocimos a José María López Piñero y las múltiples necrológicas publicadas desde su fallecimiento el pasado 8 de agosto así lo atestiguan, es en su inagotable capacidad de trabajo y en la vehemencia con que la llevaba a cabo. En una de las múltiples facetas de su labor como historiador de la medicina se refleja especialmente: su lucha por la conservación y difusión del patrimonio histórico-médico a través de la Biblioteca y el Museo de Historia de la Medicina de la Universidad de Valencia.

La Biblioteca Histórico-médica proviene de los fondos bibliográficos de la Facultad de Medicina de Valencia. Cuando en 1960 culminó su traslado desde los antiguos locales de la calle Guillén de Castro al nuevo edificio del Paseo de Valencia al Mar, José María acababa de hacerse cargo de la docencia de la Historia de la Medicina. Junto a su mujer, la profesora María Luz Terrada y la directora de la biblioteca de la Facultad, Pilar Faus, procedió a la catalogación del fondo histórico, entonces situado en el despacho de dirección, a donde se subió desde el semisótano tras la riada de 1957. Constaba de más de veinte mil libros y folletos de los siglos XV al XIX, revistas médicas y científicas, manuscritos y grabados pertenecientes a la propia Facultad, a los que se habían sumado donaciones continuadas desde 1877.

En 1975, toda la colección bibliográfica médica anterior a 1950 se trasladó a un local anexo a la Cátedra de Historia de la Medicina, aunque dependiente de la Biblioteca de la Facultad. En 1981, el decano Antonio Llombart Bosch nombró a José María responsable de este fondo bibliográfico. En los años siguientes se produjeron importantes donaciones, como las bibliotecas del cardiólogo Adolfo Rincón de Arellano y el psiquiatra 
Román Alberca o los ficheros clínicos del internista Fernando Rodríguez Fornos y el dermatólogo José Esteller Luengo. En 1982, el psiquiatra e historiador de la medicina Vicente Peset Llorca, a quien unía una estrecha amistad con José María, donó la biblioteca y papeles manuscritos de la familia, procedentes de cuatro generaciones de médicos y que constituyen el denominado fondo Peset.

En la sala central de la Biblioteca, José María y su equipo de colaboradores comenzó a exponer a partir de 1974 la colección museística de la Facultad de Medicina, que reunía instrumentos, aparatos y otras fuentes materiales e iconográficas. Gracias a las donaciones realizadas a partir de entonces, se vio enriquecida notablemente. Hay que destacar, por su especial importancia, las debidas a Domingo Campillo Valero, principal cultivador en España de la investigación paleopatológica; a los herederos del médico alcoyano Antonio Catalá Payá; al tocólogo Francisco Terrada Sebastián; al odontólogo José María Pastor Pons y a los catedráticos de patología médica Rafael Báguena Candela, de ginecología Francisco Bonilla Martí, de oftalmología Marcelo Carreras Matas, de pediatría Joaquín Colomer Sala y de farmacología Juan Esplugues Requena. Con parte de la colección, José María llevó a cabo con su equipo un montaje expositivo eminentemente didáctico, que integró en la docencia práctica de la asignatura de Historia de la Medicina y que pronto fue visitado también por institutos de enseñanza media. Se presentó la evolución histórica de la medicina a través de grandes bloques temáticos: la evolución del hombre y los estudios paleopatológicos, la materia médica popular tradicional y moderna, los sistemas médicos clásicos y la medicina de laboratorio en Valencia durante el periodo de transición del siglo XIX al XX, que incluía la tradición anatómica valenciana y la estancia de Cajal en Valencia, la paleontología y el darwinismo, la nueva terapéutica de base experimental, la repercusión de la medicina de laboratorio en el diagnóstico y la microbiología, con especial atención a la vacunación anticolérica de Ferrán.

El traslado al Hospital Clínico, a principios de los 90, de la sala de patología médica, anexa al Museo, permitió la expansión del mismo gracias a la capacidad de persuasión de José María, quien convenció al equipo decanal de una Facultad muy necesitada de espacio, de las necesidades de ampliar los locales dedicados a la colección museística. Las antiguas habitaciones de los enfermos, con apenas más inversión que una mano de pintura, se reutilizaron para reconstruir la sala de espera y el gabinete de un médico alcoyano del periodo de entreguerras y para exponer la evolución de la 
odontología y de especialidades médicas como la radiología y la medicina física, la otorrinolaringología, la urología, la obstetricia y ginecología, la revolución quirúrgica y la oftalmología.

Esta exposición permanente, que se renovaba con periodicidad, incluía los principales fondos del Museo: esculturas y modelos anatómicos procedentes del antiguo Museo Anatómico de la Facultad, grandes láminas murales didácticas como la diseñada por Santiago Ramón y Cajal acerca de la estructura del cerebelo, la memoria de oposiciones a la cátedra de Anatomía de Valencia que Cajal legó a su discípulo el profesor Bartual y éste, a la Facultad de Medicina, aparatos de laboratorio, sobre todo histológicos y microbiológicos, instrumentos para el diagnóstico, como la serie de fonendoscopios, colecciones de los siglos XIX y XX de productos medicinales naturales y quimioterápicos, como las plantas medicinales recogidas y preparadas por el propio José María durantes sus veranos en Altura, materiales de electromedicina, entre los que destacan las primeras radiografías realizadas en Valencia por Vicente Peset Cervera, colecciones de reproducciones de cráneos prehistóricos trepanados, materiales de la folkmedicina valenciana e instalaciones para la asistencia obstétrica y odontológica. Parte de estos fondos fueron utilizados en exposiciones que, bajo la dirección de José María y con la ayuda de algunos de sus colaboradores, se dedicaron a conmemorar la estancia de Ramón y Cajal en Valencia o el centenario de la vacunación anticolérica de Jaime Ferrán durante la epidemia de 1885.

Los esfuerzos realizados por José María hasta su jubilación con el fin de obtener una partida presupuestaria y un personal específicos para la Biblioteca y al Museo Histórico-médicos apenas consiguieron resultados, debido a la rígida estructura burocrática de la Universidad. Se consiguió un puesto de conservador, adscrito al ya entonces Departamento de Historia de la Ciencia y Documentación, cargo que ocupó Juan Antonio Micó Navarro, profesor titular de Historia de la Ciencia, quien con una generosidad y una dedicación ejemplares asumió todas las tareas, con la ayuda ocasional de los que entonces constituíamos la Unidad de Historia de la Ciencia, como el almacenamiento y custodia de los fondos, las gestiones relativas a donaciones y adquisiciones, la atención a los investigadores, estudiantes y visitas de grupos, la catalogación de algunos de sus fondos, etc., todo ello sin ninguna reducción de sus obligaciones docentes.

En 2001, ya jubilado José María, la Universidad de Valencia adquirió en el casco histórico de la ciudad el Palacio Cerveró para albergar el Instituto 
de Historia de la Medicina y de la Ciencia, denominado «López Piñero» en reconocimiento a su labor. Tras su restauración, se inauguró, con su presencia, en 2007 y a él se trasladó la Biblioteca y el Museo Históricomédicos que tanto deben a su fundador. 